\title{
Primary hyperparathyroidism in children and adolescents
}

\author{
Jeffrey Roizen ${ }^{\mathrm{a}}$ and Michael A. Levine ${ }^{\mathrm{b},{ }^{*}}$ \\ aDivision of Endocrinology and Diabetes, The Children's Hospital of Philadelphia, Philadelphia, \\ Pennsylvania, USA \\ bDepartment of Pediatrics, University of Pennsylvania Perelman School of Medicine, \\ Philadelphia, Pennsylvania, USA
}

\begin{abstract}
Primary hyperparathyroidism (PHPT) is a common endocrine disorder in adults in whom the typical presentation is incidentally discovered as asymptomatic hypercalcemia. PHPT is much less common in children and adolescents, but has greater morbidity in this age group, as most young patients with PHPT will have symptomatic hypercalcemia or complications such as kidney stones, abdominal pain, and skeletal fragility. An important feature of PHPT in younger patients is the relatively high prevalence of germline inactivating mutations of the $C A S R$ gene, which encodes the calcium-sensing receptor. Biallelic $C A S R$ mutations cause neonatal severe hyperparathyroidism, a life-threatening condition that presents within days of life with marked hypercalcemia, respiratory distress, failure to thrive, and skeletal demineralization. By contrast, more common heterozygous $C A S R$ mutations are generally associated with a benign variant of PHPT termed familial hypocalciuric hypercalcemia. Appropriate management of PHPT in children and adolescents requires distinction between familial hypocalciuric hypercalcemia, which generally requires no specific treatment, and other forms of PHPT that are best treated by parathyroidectomy.
\end{abstract}

\section{Keywords}

calcium sensing receptor; hypercalcemia; MEN1; osteoporosis; parathyroid; primary hyperparathyroidism; PTH

\section{Introduction}

Parathyroid hormone (PTH) is the principal calciotropic hormone, and its secretion from the parathyroid glands is tightly controlled by ambient concentrations of extracellular ionized calcium. PTH secretion is increased by hypocalcemia, and decreased by hypercalcemia, through interaction of ionized calcium with calcium-sensing receptors (CaSR) that are located on the plasma membrane of parathyroid cells. The hallmark of primary hyperparathyroidism (PHPT) is hypercalcemia, which results from the excessive secretion of PTH by one or more of the four parathyroid glands. PHPT occurs as a result of a specific defect in a parathyroid gland. Thus, PHPT is fundamentally distinct from secondary hyperparathyroidism, in which increased secretion of PTH is an adaptive response to low serum levels of calcium or vitamin D. Although serum levels of calcium and PTH are both

Copyright (C) 2012 Elsevier Taiwan LLC and the Chinese Medical Association. All rights reserved.

*Corresponding author. Dr. Michael A. Levine, Division of Endocrinology and Diabetes, The Children's Hospital of Philadelphia, $34^{\text {th }}$ and Civic Center Boulevard, Philadelphia, PA 19104, USA. levinem@ chop.edu (M.A. Levine). 
elevated in patients with tertiary hyperparathyroidism, this condition reflects a maladaptive response to antecedent hypocalcemia or vitamin D deficiency.

Our understanding of the natural history and pathophysiology of PHPT has been informed by two revolutionary events. First, the introduction of the multichannel autoanalyzer in the early 1970s enabled inexpensive and accurate biochemical measurement of many serum analytes, and encouraged routine biochemical screening of healthy adult patients. The subsequent widespread application of biochemical screening unexpectedly disclosed that large numbers of patients had asymptomatic hypercalcemia.

Second, a sensitive and reliable immunoassay for intact PTH (iPTH) was commercialized in the 1980s. This assay provided the ability to reproducibly distinguish elevated circulating concentrations of iPTH from normal concentrations. Together, these two laboratory advances transformed PHPT from a rare clinical disease associated with significant morbidity to a common biochemical disorder in which most affected patients have few signs or symptoms of excess PTH or hypercalcemia. ${ }^{1-5}$ PHPT currently is recognized as the third most common endocrine disorder in adults. PHPT is most common in patients who are between the ages of 50 and 60 years, and has an annual incidence of 30 cases per 100,000 patients, with a lifetime prevalence of approximately 1 per 1000 persons. Females outnumber males with PHPT by an approximate 3:1 ratio.

In contrast with the clinical profile of PHPT in adults, PHPT is uncommon in infants and children, with an incidence estimated at only 2-5 in 100,000 and without an apparent sex predilection (Tables 1 and 2). ${ }^{6-8,10,13-18}$ Remarkably, PHPT is clinically symptomatic in most young patients, who typically present with signs or symptoms of hypercalcemia, skeletal complications, and/or nephrolithiasis. Few if any young patients with PHPT are discovered incidentally to have asymptomatic hypercalcemia. It is unlikely that ascertainment bias, due to infrequent biochemical testing of children and adolescents, can explain the absence of asymptomatic PHPT in younger populations, as PHPT remains uncommon as late as the fourth and fifth decades of life, a time when adults begin to undergo routine biochemical screening. Therefore, we propose that there must be biologic differences that account for the distinct differences between PHPT in young and older patients.

Prior to 1984 , fewer than 150 children with PHPT had been described in the literature. ${ }^{6}$ However, over the past 30 years several large pediatric case series were published that increased the number of reported cases of PHPT in this age group to more than $300{ }^{7-18}$ The largest of the primary studies in this area comprises 55 patients, of whom 11 were infants with PHPT and 44 were young children or adolescents with PHPT. ${ }^{13}$ The largest study focusing solely on childhood and adolescent PHPT includes 52 patients. ${ }^{12}$ Although these different reports vary in the clinical characterization of PHPT, our systematic analysis of these series reveals a consistent description of the important features of pediatric PHPT.

\section{Etiology of pediatric PHPT}

Genetic syndromes that are associated with multiple abnormal parathyroid glands may account for $5-15 \%$ of all cases of PHPT, and are relatively more common in patients younger than 40 years than in older patients. ${ }^{19}$ A growing number of gene defects have been associated with PHPT, and in many cases germline or somatic mutations in the same gene can induce development of either multiple or single parathyroid adenomas, respectively. In addition, radiation exposure increases the risk of developing PHPT. The association between radiation exposure, either during childhood or adulthood, and subsequent development of PHPT in later years has been well established. ${ }^{20,21}$ By contrast, there is only a single report of childhood PHPT occurring in association with previous therapeutic radiation exposure. ${ }^{22}$ 
We reviewed selected features of PHPT in different pediatric age groups, described in the following sections.

\subsection{Neonatal severe hyperparathyroidism and familial hypocalciuric hypercalcemia}

PHPT can present within the first few days of life as neonatal severe hyperparathyroidism (NSHPT; Online Mendelian Inheritance in Man [OMIM] 239200) an uncommon disorder that is associated with severe metabolic bone disease and often life-threatening hypercalcemia (greater than $20 \mathrm{mg} / \mathrm{dL}$ ). The diagnosis of NSHPT is based on the presence of elevated PTH levels along with relative hypocalciuria in an infant with hypercalcemia. A family history of early-onset hypercalcemia in a sibling or parent can provide strong confirmation of the diagnosis. Care must be taken to distinguish these disorders from the transient neonatal hyperparathyroidism associated with maternal hypocalcemia, as seen in mothers with severe vitamin D deficiency or hypoparathyroidism. In all cases that have been analyzed, NSHPT has been associated with inactivating mutations in the $C A S R$ gene (http:// www.casrdb.mcgill.ca/) located at 3p13.3 (OMIM 601198). The CASR gene encodes CaSR, which is a member of family $\mathrm{C}$ of the heptahelical G-protein-coupled receptors (GPCRs) that also includes the metabotropic glutamate receptors (mGluR), $\gamma$-aminobutyric acid (GABA)B receptors, and many olfactory, pheromone, and taste receptors (www.GPCR.org). The CaSR is widely distributed throughout the body, but its principal function appears related to regulation of calcium homeostasis through its expression on the plasma membranes of parathyroid and renal tubule cells. Activation of the parathyroid CaSR by extracellular ionized calcium $\left(\mathrm{Ca}^{2+}\right)$ inhibits secretion of $\mathrm{PTH}$, while in the distal renal tubule cells receptor activation leads to enhanced urinary excretion of calcium.

In most cases, neonates with NSHPT have inactivating mutations on both CASR alleles, which results in a complete or near-complete absence of functional CaSRs on parathyroid and other cells in the body. The loss of calcium sensing leads to parathyroid hyperplasia and increased PTH secretion as well as decreased renal excretion of calcium, and consequently severe hypercalcemia ensues. Some infants with NSHPT have been described who possess only a single defective $C A S R$ allele. In these cases the mutant $C A S R$ was inherited from an affected father or arose as a de novo mutation. Presumably, exposure of the affected fetus to normal maternal calcium concentrations intensifies development of hyperparathyroidism in utero and leads to severe hypercalcemia after birth. ${ }^{23-27}$ Other NSHPT infants with monoallelic CASR mutations have de novo or paternally inherited CASR missense mutations that replace the normal arginine at codon 185 with a glutamine residue (R185Q). ${ }^{26,28-30}$ The R185Q mutation is particularly significant because it acts as a dominant inhibitor, thereby suppressing function of the normal CaSRs that are produced by the wild type $C A S R$ allele.

Although heterozygous $C A S R$ mutations can cause NSHPT, monoallelic mutations are more commonly associated with a relatively asymptomatic form of PHPT that has been termed familial hypocalciuric hypercalcemia $(\mathrm{FHH})$, sometimes also termed benign familial hypercalcemia (FHH/HHC1; OMIM 145979). FHH is therefore genetically related to NSHPT and its mildness is thought to represent a dose affect of the inactivating $C A S R$ mutations. Hence, FHH is typically an autosomal dominant condition, ${ }^{31,32}$ although very mild CASR mutations have been associated with an autosomal recessive form of $\mathrm{FHH} .{ }^{33}$ In both FHH and NSHPT, hypercalcemia arises due to decreased calcium sensing in the parathyroid glands, the kidney, the skeleton, and perhaps other tissues. ${ }^{34}$ Specifically, lack of calcium-mediated signaling leads to enlargement of all four (or more) parathyroid glands and either modest (FHH) or markedly (NSHPT) increased secretion of PTH. Concurrently, the fractional renal clearance of calcium $(\mathrm{FeCa})$ is reduced to less than $1 \%$ due to the loss of $\mathrm{CaSR}$ action in the distal renal tubule. Increased circulating concentrations of PTH act on the kidney and skeleton to increase serum calcium. This effect, combined with decreased 
renal calcium clearance and possibly decreased secretion of calcitonin, leads to the development of severe hypercalcemia and metabolic bone disease in NSHPT and only mild (and generally asymptomatic) hypercalcemia in $\mathrm{FHH}^{35}$

\subsection{Childhood/adolescent PHPT}

Childhood/adolescent PHPT is associated with either single parathyroid adenomas or multiple adenomas (so-called parathyroid hyperplasia). In many cases the precise molecular defect can be identified, and is either a somatic mutation that is limited to the parathyroid adenoma or a germline mutation that was inherited or arose de novo in the parathyroid gland. Thus, the etiology of PHPT includes (1) multigland hyperplasia resulting from germline mutations in the MENIN, RET, and CDKN1B (encoding p27Kip1) genes; (2) single parathyroid adenomas that represent monoclonal neoplasms, many of which are associated with somatic mutation in MENIN or PRAD1; and (3) distinct parathyroid adenomas due to germ-line or somatic mutations in HPRT2 (CDC 73) and which have a predisposition to parathyroid carcinoma (Table 3 ).

FHH must be distinguished from other forms of PHPT in this age group, because FHH is usually an asymptomatic condition and is managed differently from true PHPT. In contrast with most patients with PHPT, patients with FHH have circulating concentrations of PTH that are normal or only slightly elevated. However, in the presence of hypercalcemia such concentrations are inappropriately high and indicate that the set-point of the parathyroid calciostat regulating PTH secretion functions at a higher than normal level (see previous paragraph). The hypercalcemia and hypophosphatemia are similar in magnitude to those found in mild cases of PHPT. Most patients have no symptoms attributable to the hypercalcemia, although it is rare that patients experience mild muscle weakness and easy fatiguability. In contrast with patients with PHPT, patients with FHH tend to have elevated plasma levels of magnesium. The key diagnostic feature of FHH is the very low (i.e. generally less than $1 \%$ ) fractional excretion of calcium (FeCa) by the kidney. However, normal or even elevated urinary calcium excretion has been described in members of several FHH kindreds, ${ }^{36,37}$ and hypocalciuria can be present in some patients with common PHPT who also have vitamin D insufficiency. Therefore, hypocalciuria is not an absolute criterion. The urinary calcium excretion is usually less than $100 \mathrm{mg} / 24$ hour ( $25 \mathrm{mmol} / 24$ hour), in contrast with true PHPT, where it is usually greater than $120 \mathrm{mg} / 24$ hours. The plasma level of calcitriol in FHH is usually in the mid-normal range in contrast to a tendency to elevated levels in PHPT. Further confusion between FHH and PHPT derives from recent reports of the development of classic parathyroid adenomas and symptomatic PHPT in some teens and adults with $\mathrm{FHH}$, however. ${ }^{38,39}$

Multiple endocrine neoplasia, or MEN1 (OMIM 131099), is the most common cause of inherited PHPT. PHPT is present in more than $90 \%$ of patients, and diffuse hyperplasia or multiple adenomas are more common than solitary adenomas. PHPT is rare in the first decade of life. Pancreatic islet cell tumors occur in $60-70 \%$ of patients and are usually multi-centric. Multiple adenomas or diffuse islet cell hyperplasia commonly occurs, and approximately $30 \%$ of tumors are malignant and have local or distant metastases. Approximately $40 \%$ of islet cell tumors are insulinomas, which are more common in patients younger than 40 years. Approximately $60 \%$ of islet cell tumors originate from non$\beta$-cell elements and tend to occur in patients older than 40 years. Pituitary tumors occur in $15-42 \%$ of MEN1 patients. Prolactinomas are the most common pituitary tumors, and approximately $25 \%$ of pituitary tumors secrete growth hormone or growth hormone and prolactin. Additional features of MEN1 include carcinoid tumors, particularly those derived from the embryologic foregut, and subcutaneous and visceral lipomas, angiofibromas, and collagenomas. Some patients with MEN1 who do not have mutations in MENIN may have 
mutations in $C D K N 1 B$, which encodes cyclin-dependent kinase inhibitor 1B. This enzyme belongs to the Cip/Kip family of cyclin dependent kinase (Cdk) inhibitor proteins.

PHPT is relatively uncommon in MEN2a (OMIM 171399), occurring in only 20-30\% of patients, and almost never occurs in MEN2b (OMIM 162299). Generally all four parathyroid glands are affected, but metasynchronous or asynchronous parathyroid involvement is common. PHPT is usually diagnosed after the third decade of life, and although it can occur in children this is a rare finding. PHPT is less severe in MEN2a than in MEN1. The highest prevalence of PHPT occurs in patients who carry the codon 634 RET gene mutation. Medullary thyroid carcinoma is the most common feature of MEN2a, occurring in more than $90 \%$ of patients. Pheochromocytoma occurs in approximately 50\% of patients.

Germline mutations of the HRPT2 gene cause the hyperparathyroidism-jaw tumor (HPT-JT) syndrome (OMIM 145010). ${ }^{40,41}$ HPT-JT is an uncommon autosomal dominant syndrome characterized by PHPT due to parathyroid adenomas and fibro-osseous lesions of the maxilla and mandible. Patients with HPT-JT may also develop other manifestations including renal tumors and cysts and uterine tumors. The syndrome typically develops in late adolescence or early adulthood. Parathyroid tumors, most often single adenomas, occur in up to $95 \%$ of patients with HPT-JT. Parathyroid carcinoma occurs in approximately $15 \%$ of cases. Some patients with familial isolated PHPT also have HRPT2 mutations.

Interestingly, somatic mutations in some of the genes implicated in multiglandular PHPT (MENIN, HPRT2, and CDKN1B) can cause solitary parathyroid adenomas when they occur as somatic mutations. This occurrence serves to emphasize that the histologic distinction between parathyroid adenoma and parathyroid hyperplasia may not be real, and certainly is not useful in predicting single versus multiple gland disease as both variants can arise from the same mutation.

\section{Pathology}

In most cases, PHPT will result from a single benign parathyroid adenoma (90\%); multiple adenomas occur rarely (approximately 2-4\%). Involvement of all four parathyroid glands, so-called parathyroid hyperplasia, occurs in approximately $10 \%$ of patients, but may be metasynchronous or asynchronous. Parathyroid carcinoma is exceedingly uncommon (less than $1 \%)$.

\subsection{Neonatal severe hyperparathyroidism and familial hypocalciuric hypercalcemia}

Traditionally, the abnormal parathyroid glands in NSHPT and FHH have been described as hyperplastic, but this characterization may have been based on enlargement of all four (or more) glands rather than specific histologic features. The abnormal glands are benign tumors.

\subsection{Childhood/adolescent PHPT}

Most cases of childhood/adolescent PHPT, like adult PHPT, are associated with a single parathyroid adenoma (196 of 213; 92\%; Table 4) ${ }^{6,8-10,12-18}$ Patients with multigland disease usually have germline mutations associated with genetic syndromes such as MEN1 and MEN2a as well as familial hyperparathyroidism. In nearly all cases, including children with HPT-JT syndrome, the parathyroid tumors are benign. Parathyroid carcinoma occurs in fewer than $1 \%$ of parathyroid tumors in adults, ${ }^{42}$ and is usually associated with either somatic or germline mutations in HPRT2 (CDC 73). ${ }^{43}$ 


\section{Clinical features/complications}

\subsection{Neonatal severe hyperparathyroidism}

The clinical features of NSHPT include failure to thrive, hypotonia, respiratory distress, and prominent skeletal involvement. Serum levels of intact PTH and calcium are markedly elevated, and marked bone demineralization or fractures are present at birth or soon thereafter. Hypercalcemia often requires urgent intervention.

Three series of patients with NSHPT have been published. ${ }^{6,13,44}$ Of these series, two studies are compilations of previously published patients ${ }^{6,44}$ and Mallet's series ${ }^{13}$ is a primary study. At diagnosis, the most common clinical characteristics in patients described in these series (Table 5) $)^{12,13}$ were skeletal abnormalities (82\%), followed by hypotonia (55\%) and failure to thrive $(43 \%)$.

\subsection{Childhood/adolescent PHPT}

As described previously, childhood/adolescent PHPT often presents with vague symptoms. These symptoms usually include bone pain and abdominal pain. In recent series, however, almost $15 \%$ of patients have lacked symptoms at the time of diagnosis, with PHPT diagnosis following incidentally discovered hypercalcemia (Table 6) ${ }^{7-18}$. Despite this group of patients reportedly having few or no symptoms, most of these patients showed skeletal ( 88 of $117 ; 75 \%$ ) or renal ( 60 of $134 ; 45 \%$ ) pathology (Table 7) $7,9,12-14,16$. Biochemically, these patients manifest hypercalcemia, hypophosphatemia hypercalciuria, and either elevated or inappropriately normal concentrations of iPTH (Table 8) ${ }^{7-18}$. In contrast with adult PHPT, in which an approximate 3:1 female predominance occurs, sex distribution appears to be nearly equal in pediatric PHPT (Table 2).

\section{Ascertainment and diagnosis}

The critical biochemical features of PHPT are an elevated (or inappropriately normal) level of serum iPTH in the context of a high-normal or elevated serum calcium concentration. FHH and NSHPT are characterized by very low urinary calcium excretion (fractional excretion of calcium ( $\mathrm{FeCa}$ ) of less than $1 \%),{ }^{45-48}$ whereas other forms of PHPT usually have higher levels of urinary calcium (FeCa greater than $1 \%$ ). Urine levels of calcium can be low in some patients with PHPT, particularly when there is coexisting vitamin D insufficiency. Many patients with FHH or NSHPT will also have an affected first-degree relative.

Both NSHPT and PHPT in childhood/adolescence usually present with clinically significant morbidity; patients with FHH are generally asymptomatic and a diagnosis is made either on the basis of an affected family member or the serendipitous discovery of mild hypercalcemia during biochemical screening for an unrelated condition. In NSHPT the symptoms are often vague and include failure to thrive, respiratory distress, or severe metabolic bone disease. Patients with childhood or adolescent PHPT tend to have signs or symptoms of hyperparathyroidism or hypercalcemia at the time of initial presentation, with our assessment of recent publications (summarized in Table 6) indicating that only approximately $15 \%$ of patients are asymptomatic. By contrast, more than $80 \%$ of adults with PHPT are asymptomatic. ${ }^{49}$

Classically, the symptoms reported by children or adolescents with PHPT are conveniently recalled using the phrase "stones, bones, abdominal groans, thrones, and psychiatric overtones." These terms refer to kidney stones, metabolic bone disease (reduced bone density, fractures, or rarely osteitis fibrosa cystic), abdominal pain (due to gastric hyperacidity, pancreatitis, or constipation), polyuria, and cognitive or psychiatric 
dysfunction. However, pediatric case reports also describe a wide range of additional vague or nonspecific features.

The biochemical features of pediatric PHPT mirror those of the adult form; patients have hypercalciuria, hypercalcemia, hypophosphatemia, and either inappropriately normal or elevated iPTH concentrations in the context of hypercalcemia. In recent large studies investigating the changing biochemistry of PHPT in adults, the serum calcium, serum ionized calcium, and serum PTH concentrations at presentation for surgery were $2.8 \mathrm{mmol} / \mathrm{L}$ (normal range $2.1-2.6$ ) ${ }^{50} 1.45 \mathrm{nmol} / \mathrm{L}$ (normal range 1.15-1.2), and $103 \mathrm{pg} / \mathrm{mL}$ (normal range 15-65), respectively. ${ }^{51}$ For comparison, in the studies reviewed here, the average serum calcium, serum ionized calcium, and serum PTH concentrations at presentation in children and adolescents were $3.27 \mathrm{mmol} / \mathrm{L}(n=226$, normal range $2.1-2.6), 1.56 \mathrm{nmol} / \mathrm{L}$ ( $n$ $=59$, normal range $1.15-1.2)$, and $200 \mathrm{pg} / \mathrm{mL}$ ( $n=156$, normal range 10-70), respectively. The increased magnitude of deviation from the normal range observed in childhood and adolescent PHPT biochemical measurements is consistent with the idea that PHPT is more severe in children and adolescents than in adults.

\section{Management and outcome}

\subsection{Neonatal severe hyperparathyroidism}

Early surgical intervention with subtotal parathyroidectomy was the standard treatment of

NSHPT before the invention of potent intravenous bisphosphonates. ${ }^{52}$ Although surgery remains curative for this disease, however, total resection of all enlarged parathyroid glands leads to hypoparathyroidism. Evidence suggests that in many cases of NSHPT surgery can be postponed or obviated through the use of intravenous bisphosphonates to reduce serum calcium. ${ }^{29,52}$ An alternative that has reported with less success is treatment with a calciumpoor diet concurrent with close biochemical monitoring. Interestingly, recent studies in a single adolescent ${ }^{53}$ and in adult patients ${ }^{54}$ with PHPT have shown that mild hypercalcemia can be managed using type II calcimimetic compounds. Although type I calcimimetics are direct receptor agonists, type II calcimimetics (such as cinacalcet) are allosteric modifiers that reduce the threshold for CaSR activation by $\mathrm{Ca}^{2+}$ by increasing the affinity of the receptor for calcium. Recent case reports suggest a role for these agents as medical alternatives or adjuncts to surgery or bisphosphonates to control hypercalcemia in neonates and infants with NSHPT due to heterozygous inactivating mutations of the CASR gene. ${ }^{28,30}$ Although calcimimetics are able to control hypercalcemia, the long-term effects of these agents on skeletal integrity remain unknown. Some studies of these compounds in experimental animal models of hyperparathyroidism imply that calcimimetics may contribute to structural bone disease despite normalizing serum calcium and PTH concentrations. ${ }^{55,56}$

\subsection{Childhood/adolescent PHPT}

Surgery is curative in most pediatric and adult patients with PHPT, although patients with MEN1 will usually require more than one surgery when initial parathyroidectomy is conservative (Table 9) ${ }^{7,9-16}$. The preoperative identification of a single parathyroid adenoma, usually by $99 \mathrm{~m}$ Tc-sestamibi scan or neck ultrasonography, allows consideration of minimally invasive parathyroid surgery instead of a conventional bilateral neck exploration. Sestamibi is absorbed faster by a hyper-functioning parathyroid gland than by a normal parathyroid gland. Moreover, sestamibi is retained by an abnormal parathyroid gland for a longer period of time than by the surrounding normal thyroid tissue. Uptake of sestamibi correlates with the number and activity of the mitochondria within the parathyroid cells. Hence, chief cell parathyroid adenomas have a very high avidity for sestamibi, whereas oxyphil/clear cell parathyroid adenomas have almost no imaging quality at all with 
sestamibi. Approximately $60-80 \%$ of parathyroid adenomas can be identified by sestamibi scanning. Specific limitations to success include multiglandular parathyroid disease and a small parathyroid adenoma. The use of single-photon emission computed tomography (three dimensional) as an adjunct to planar methods appears to increase sensitivity and accuracy, especially in cases of small parathyroid adenomas or adenomas that are located in ectopic sites. In most centers, minimally invasive parathyroid surgery is performed using intraoperative measurement of PTH levels to confirm successful parathyroidectomy.

\section{Outcomes}

\subsection{Neonatal severe hyperparathyroidism}

Descriptions of NSHPT that were published before the introduction of automated methods for measurement of serum calcium in 1984 reported mortality rates of approximately $50 \%$ (Table 10) ${ }^{6,13}$. In fact, almost half of these deaths, or $25 \%$ of total reported cases, occurred in infants who did not have a diagnosis of hypercalcemia prior to death. By contrast, the most recent series on NSHPT report no mortality among patients with NSHPT. ${ }^{13}$ Thus, improved outcomes in NSHPT have resulted from the availability of simple assays for serum calcium, and the common practice of measuring serum calcium concentrations in infants who are failing to thrive. In neonates of parents with FHH, early screening of serum calcium allows rapid diagnosis and early initiation of treatment. A mutation in the $C A S R$ gene is the cause of most cases of NSHPT, ${ }^{23-27}$ and was identified in $75 \%$ of infants with neonatal PHPT reviewed here.

\subsection{Childhood/adolescent PHPT}

Parathyroidectomy is the treatment of choice in children with PHPT. Because PHPT is generally more severe in this age group, children are at significant risk of postoperative hungry bone syndrome (approximately 50\%) and acute hypocalcemia (Table 9 - nearly $50 \%$ ). In addition, some patients will develop either persistent hypocalcemia $(2 \%)$ or hypercalcemia (3\%). Finally, although bone mass improves significantly in adults after successful parathyroidectomy, ${ }^{57,58}$ similar studies in pediatric patients with PHPT are lacking.

In conclusion, PHPT is far less common in the pediatric population than in the adult population, and likely constitutes less than 5\% of all cases of PHPT. ${ }^{10}$ PHPT appears to be a more aggressive disorder in children than in adults, in whom most cases currently are incidentally ascertained by routine biochemical screening. In the context of hypercalcemia and suspicion of PHPT, it is important to exclude the diagnosis of FHH, as patients with this disorder will generally not benefit from surgical intervention. When surgical management is indicated, we recommend that parathyroidectomy be performed in a large-volume center by an experienced surgeon to enhance the probability of cure.

\section{References}

1. Heath H, Hodgson SF, Kennedy MA. Primary hyperparathyroidism. Incidence, morbidity, and potential economic impact in a community. N Engl J Med. 1980; 302:189-93. [PubMed: 7350459]

2. Parfitt MA, Rao DS, Kleerekoper M. Asymptomatic primary hyperparathyroidism discovered by multichannel biochemical screening: clinical course and considerations bearing on the need for surgical intervention. J Bone Miner Res. 1991; 6(S2):S97-101. [PubMed: 1763676]

3. Ljunghall S, Hellman P, Rastad J, Akerström G. Primary hyperparathyroidism: epidemiology, diagnosis and clinical picture. World J Surg. 1991; 15:681-7. [PubMed: 1767533]

4. Wermers RA, Khosla S, Atkinson EJ, Achenbach SJ, Oberg AL, Grant CS, et al. Incidence of primary hyperparathyroidism in Rochester, Minnesota, 1993-2001: an update on the changing epidemiology of the disease. J Bone Miner Res. 2005; 21:171-7. [PubMed: 16355286] 
5. Wermers RA, Khosla S, Atkinson EJ, Hodgson SF, O'Fallon WM, Melton LJ. The rise and fall of primary hyperparathyroidism: a population-based study in Rochester, Minnesota, 1965-1992. Ann Intern Med. 1997; 126:433-40. [PubMed: 9072928]

6. Girard RM, Belanger A, Hazel B. Primary hyperparathyroidism in children. Can J Surg. 1982; 25:11-3. 32. [PubMed: 7055756]

7. Venail F, Nicollas R, Morin D, Mackle T. Solitary parathyroid adenoma: a rare cause of primary hyperparathyroidism in children. Laryngoscope. 2007; 117:946-9. [PubMed: 17473702]

8. Cronin CS, Reeve TS, Robinson B, Clifton-Bligh P, Guinea A, Delbridge L. Primary hyperparathyroidism in childhood and adolescence. J Paediatr Child Health. 1996; 32:397-9. [PubMed: 8933398]

9. Lawson M, Miller S, Ellis G, Filler R. Primary hyperparathyroidism in a paediatric hospital. QJM. 1996; 89:921-32. [PubMed: 9015486]

10. Loh K-C, Duh Q-Y, Shoback D, Gee L, Siperstein A, Clark OH. Clinical profile of primary hyperparathyroidism in adolescents and young adults. Clin Endocrinol. 1998; 48:435-43.

11. Harman CR, van Heerden JA, Farley DR, Grant CS, Thompson GB, Curlee K. Sporadic primary hyperparathyroidism in young patients: a separate disease entity? Arch Surg. 1999; 134:651-5. [PubMed: 10367876]

12. Kollars J, Zarroug A, van Heerden J, Lteif A, Stavlo P, Suarez L, et al. Primary hyperparathyroidism in pediatric patients. Pediatrics. 2005; 115:974-80. [PubMed: 15805373]

13. Mallet E. Working Group on Calcium Metabolism. Primary hyperparathyroidism in neonates and childhood. The French experience (1984-2004). Horm Res. 2008; 69:180-8. [PubMed: 18219222]

14. Bhadada SK, Bhansali A, Dutta P, Behera A, Chanukya GV, Mittal BR. Characteristics of primary hyperparathyroidism in adolescents. J Pediatr Endocrinol Metab. 2008; 21:1147-53. [PubMed: 19189688]

15. George J, Acharya SV, Bandgar TR, Menon PS, Shah NS. Primary hyperparathyroidism in children and adolescents. Indian J Pediatr. 2010; 77:175-8. [PubMed: 20091382]

16. Li CC, Yang C, Wang S, Zhang J, Kong XR, Ouyang JA. 10-year tetrospective study of primary hyperparathyroidism in children. Exp Clin Endocrinol Diabetes. 2012; 120:229-33. [PubMed: 22328111]

17. Hsu SC, Levine MA. Primary hyperparathyroidism in children and adolescents: the Johns Hopkins Children's Center experience 1984-2001. J Bone Miner Res. 2002; 17(Suppl):N44-50. [PubMed: 12412777]

18. Durkin ET, Nichol PF, Lund DP, Chen H, Sippel RS. What is the optimal treatment for children with primary hyperparathyroidism? J Pediatr Surg. 2010; 45:1142-6. [PubMed: 20620309]

19. Starker LF, Akerström T, Long WD, Delgado-Verdugo A, Donovan P, Udelsman R, et al. Frequent germ-line mutations of the MEN1, CASR, and HRPT2/CDC73 genes in young patients with clinically non-familial primary hyperparathyroidism. Horm Cancer. 2012; 3:44-51. [PubMed: 22187299]

20. Beard CM, Heath H, O'Fallon WM, Anderson JA, Earle JD, Melton LJ 3rd. Therapeutic radiation and hyperparathyroidism. A case-control study in Rochester, Minn. Arch Intern Med. 1989; 149:1887-90. [PubMed: 2764660]

21. McMullen T, Bodie G, Gill A, Ihre-Lundgren C, Shun A, Bergin M, et al. Hyperparathyroidism after irradiation for childhood malignancy. Int J Radiat Oncol Biol Phys. 2009; 73:1164-8. [PubMed: 18774659]

22. Gillis D, Hirsch HJ, Landau H, Schiller M, Lebensart PD, Peylan-Ramu N. Parathyroid adenoma after radiation in an 8-year-old boy. J Pediatr. 1998; 132:892-3. [PubMed: 9602210]

23. Hannan FM, Nesbit MA, Christie PT, Lissens W, Van der Schueren B, Bex M, et al. A homozygous inactivating calcium-sensing receptor mutation, Pro339Thr, is associated with isolated primary hyperparathyroidism: correlation between location of mutations and severity of hypercalcaemia. Clin Endocrinol. 2010; 73:715-22.

24. Ho C, Conner DA, Pollak MR, Ladd DJ, Kifor O, Warren HB, et al. A mouse model of human familial hypocalciuric hypercalcemia and neonatal severe hyperparathyroidism. Nat Genet. 1995; 11:389-94. [PubMed: 7493018] 
25. Pollak MR, Chou YH, Marx SJ, Steinmann B, Cole DE, Brandi ML, et al. Familial hypocalciuric hypercalcemia and neonatal severe hyperparathyroidism. Effects of mutant gene dosage on phenotype. J Clin Invest. 1994; 93:1108-12. [PubMed: 8132750]

26. Pollak MR, Brown EM, Chou YH, Hebert SC, Marx SJ, Steinmann B, et al. Mutations in the human $\mathrm{Ca} 2+-$ sensing receptor gene cause familial hypocalciuric hypercalcemia and neonatal severe hyperparathyroidism. Cell. 1993; 75:1297-303. [PubMed: 7916660]

27. Chou YH, Pollak MR, Brandi ML, Toss G, Arnqvist H, Atkinson AB, et al. Mutations in the human $\mathrm{Ca}(2+)$-sensing-receptor gene that cause familial hypocalciuric hypercalcemia. Am J Hum Genet. 1995; 56:1075-9. [PubMed: 7726161]

28. Reh CMS, Hendy GN, Cole DEC, Jeandron DD. Neonatal hyperparathyroidism with a heterozygous calcium-sensing receptor (CASR) R185Q mutation: clinical benefit from Cinacalcet. J Clin Endocrinol Metab. 2011; 96:E707-12. [PubMed: 21289269]

29. Obermannova B, Banghova K, Sumník Z, Dvorakova HM, Betka J, Fencl F, et al. Unusually severe phenotype of neonatal primary hyperparathyroidism due to a heterozygous inactivating mutation in the CASR gene. Eur J Pediatr. 2009; 168:569-73. [PubMed: 18751724]

30. Gannon, A.; Levine, MA. Pediatric Academic Societies Abstract - prepublication: E-PAS2012. 2012. Successful treatment of neonatal severe hyperparathyroidism with Cinacalcet monotherapy. [unknown]

31. Pidasheva S, D'Souza-Li L, Canaff L, Cole DEC, Hendy GN. CASRdb: calcium-sensing receptor locus-specific database for mutations causing familial (benign) hypocalciuric hypercalcemia, neonatal severe hyperparathyroidism, and autosomal dominant hypocalcemia. Hum Mutat. 2004; 24:107-11. [PubMed: 15241791]

32. Felderbauer P, Hoffmann P, Klein W, Bulut K, Ansorge N, Epplen JT, et al. Identification of a novel calcium-sensing receptor gene mutation causing familial hypocalciuric hypercalcemia by single-strand conformation polymorphism analysis. Exp Clin Endocrinol Diabetes. 2005; 113:314. [PubMed: 15662592]

33. Lietman SA, Tenenbaum-Rakover Y, Jap TS, Yi-Chi W, De-Ming Y, Ding C, et al. A novel lossof-function mutation, Gln459Arg, of the calcium-sensing receptor gene associated with apparent autosomal recessive inheritance of familial hypocalciuric hypercalcemia. J Clin Endocrinol Metab. 2009; 94:4372-9. [PubMed: 19789209]

34. Kantham L, Quinn SJ, Egbuna OI, Baxi K, Butters R, Pang JL, et al. The calcium-sensing receptor (CaSR) defends against hypercalcemia independently of its regulation of parathyroid hormone secretion. Am J Physiol Endocrinol Metab. 2009; 297:E915-23. [PubMed: 19797241]

35. Brown EM. The calcium-sensing receptor: physiology, pathophysiology and CaR-based therapeutics. Subcell Biochem. 2007; 45:139-67. [PubMed: 18193637]

36. Pasieka JL, Andersen MA, Hanley DA. Familial benign hypercalcaemia: hypercalciuria and hypocalciuria in affected members of a small kindred. Clin Endocrinol. 1990; 33:429-33.

37. Carling T. Familial hypercalcemia and hypercalciuria caused by a novel mutation in the cytoplasmic tail of the calcium receptor. J Clin Endocrinol Metab. 2000; 85:2042-7. [PubMed: 10843194]

38. Brachet C, Boros E, Tenoutasse S, Lissens W, Andry G, Martin P, et al. Association of parathyroid adenoma and familial hypocalciuric hypercalcaemia in a teenager. Eur J Endocrinol. 2009; 161:207-10. [PubMed: 19423559]

39. Frank-Raue K, Leidig-Bruckner G, Haag C, Schulze E, Lorenz A, Schmitz-Winnenthal H, et al. Inactivating calcium-sensing receptor mutations in patients with primary hyperparathyroidism. Clin Endocrinol. 2011; 75:50-5.

40. Iacobone M, Masi G, Barzon L, Porzionato A, Macchi V, Ciarleglio FA, et al. Hyperparathyroidism-jaw tumor syndrome: a report of three large kindred. Langenbecks Arch Surg. 2009; 394:817-25. [PubMed: 19529956]

41. Cetani F, Pardi E, Giovannetti A, Vignali E, Borsari S, Golia F, et al. Genetic analysis of the MEN1 gene and HPRT2 locus in two Italian kindreds with familial isolated hyperparathyroidism. Clin Endocrinol. 2002; 56:457-64.

42. Wei $\mathrm{CH}$, Harari A. Parathyroid carcinoma: update and guidelines for management. Curr Treat Options Oncol. 2012; 13:11-23. [PubMed: 22327883] 
43. Westin G, Björklund P, Akerström G. Molecular genetics of parathyroid disease. World J Surg. 2009; 33:2224-33. [PubMed: 19373510]

44. Norwood S, Andrassy RJ. Primary hyperparathyroidism in children: a review. Mil Med. 1983; 148:812-4. [PubMed: 6417570]

45. Marcocci C, Cetani F. Clinical practice. Primary hyperparathyroidism. N Engl J Med. 2011; 365:2389-97. [PubMed: 22187986]

46. Marx SJ, Attie MF, Levine MA, Spiegel AM, Downs RW, Lasker RD. The hypocalciuric or benign variant of familial hypercalcemia: clinical and biochemical features in fifteen kindreds. Medicine (Baltimore). 1981; 60:397-412. [PubMed: 7311809]

47. Marx SJ, Spiegel AM, Brown EM, Windeck R, Gardner DG, Downs RW, et al. Circulating parathyroid hormone activity: familial hypocalciuric hypercalcemia versus typical primary hyperparathyroidism. J Clin Endocrinol Metab. 1978; 47:1190-7. [PubMed: 233692]

48. Marx SJ, Attie MF, Stock JL, Spiegel AM, Levine MA. Maximal urine-concentrating ability: familial hypocalciuric hypercalcemia versus typical primary hyperparathyroidism. J Clin Endocrinol Metab. 1981; 52:736-40. [PubMed: 6259192]

49. Rubin MR, Bilezikian JP, McMahon DJ, Jacobs T, Shane E, Siris E, et al. The natural history of primary hyperparathyroidism with or without parathyroid surgery after 15 years. J Clin Endocrinol Metab. 2008; 93:3462-70. [PubMed: 18544625]

50. Mazzaglia PJ, Berber E, Kovach A, Milas M, Esselstyn C, Siperstein AE. The changing presentation of hyperparathyroidism over 3 decades. Arch Surg. 2008; 143:260. [PubMed: $18347273]$

51. Almquist M, Bergenfelz A, Mårtensson H, Thier M, Nordenström E. Changing biochemical presentation of primary hyperparathyroidism. Langenbecks Arch Surg. 2010; 395:925-8. [PubMed: 20623136]

52. Waller S, Kurzawinski T, Spitz L, Thakker R, Cranston T, Pearce S, et al. Neonatal severe hyperparathyroidism: genotype/phenotype correlation and the use of pamidronate as rescue therapy. Eur J Pediatr. 2004; 163:589-94. [PubMed: 15241688]

53. Henrich LM, Rogol AD, D’Amour P, Levine MA, Hanks JB, Bruns DE. Persistent hypercalcemia after parathyroidectomy in an adolescent and effect of treatment with Cinacalcet $\mathrm{HCl}$. Clin Chem. 2006; 52:2286-93. [PubMed: 17105782]

54. Peacock M, Bilezikian JP, Bolognese MA, Borofsky M, Scumpia S, Sterling LR, et al. Cinacalcet $\mathrm{HCl}$ reduces hypercalcemia in primary hyperparathyroidism across a wide spectrum of disease severity. J Clin Endocrinol Metab. 2011; 96:E9-18. [PubMed: 20943783]

55. Finch JL, Tokumoto M, Nakamura H, Yao W, Shahnazari M, Lane N, et al. Effect of paricalcitol and cinacalcet on serum phosphate, FGF-23, and bone in rats with chronic kidney disease. Am J Physiol Renal Physiol. 2010; 298:F1315-22. [PubMed: 20200094]

56. Goltzman D. Do calcimimetics directly alter bone remodling? Am J Physiol Renal Physiol. 2010; 298:F1313-4. [PubMed: 20237238]

57. Nakaoka D. Prediction of bone mass change after parathyroidectomy in patients with primary hyperparathyroidism. J Clin Endocrinol Metab. 2000; 85:1901-7. [PubMed: 10843172]

58. Silverberg SJ, Gartenberg F, Jacobs TP, Shane E, Siris E, Staron RB, et al. Increased bone mineral density after parathyroidectomy in primary hyperparathyroidism. J Clin Endocrinol Metab. 1995; 80:729-34. [PubMed: 7883824] 


\section{Table 1}

Sex distribution of NSHPT in infants.

\begin{tabular}{llll}
\hline & Girard et al $^{\mathbf{6}}$ & Mallet $^{\mathbf{1 3}}$ & Total \\
\hline Males & $8 / 17$ & $4 / 11$ & $12 / 28(43 \%)$ \\
Females & $9 / 17$ & $7 / 11$ & $16 / 28(57 \%)$ \\
\hline
\end{tabular}




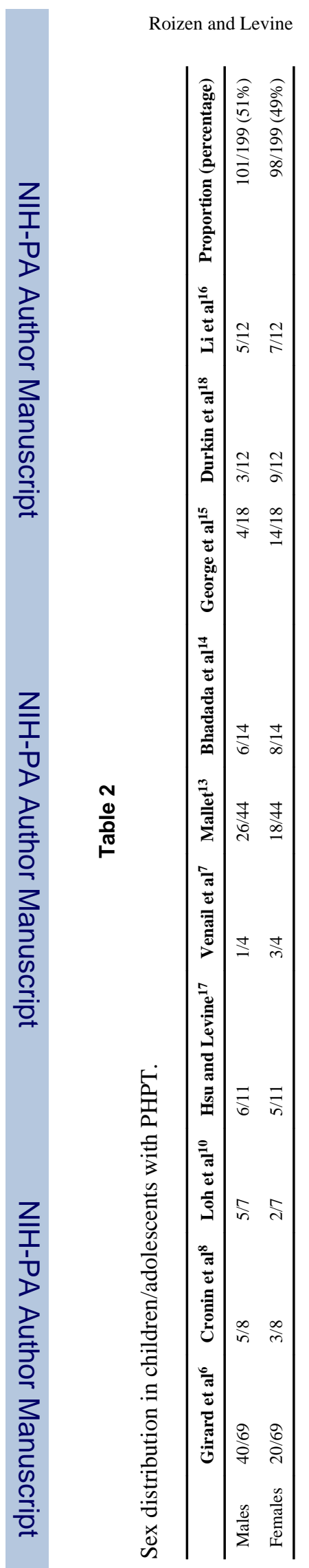

Page 13

J Chin Med Assoc. Author manuscript; available in PMC 2013 July 12. 


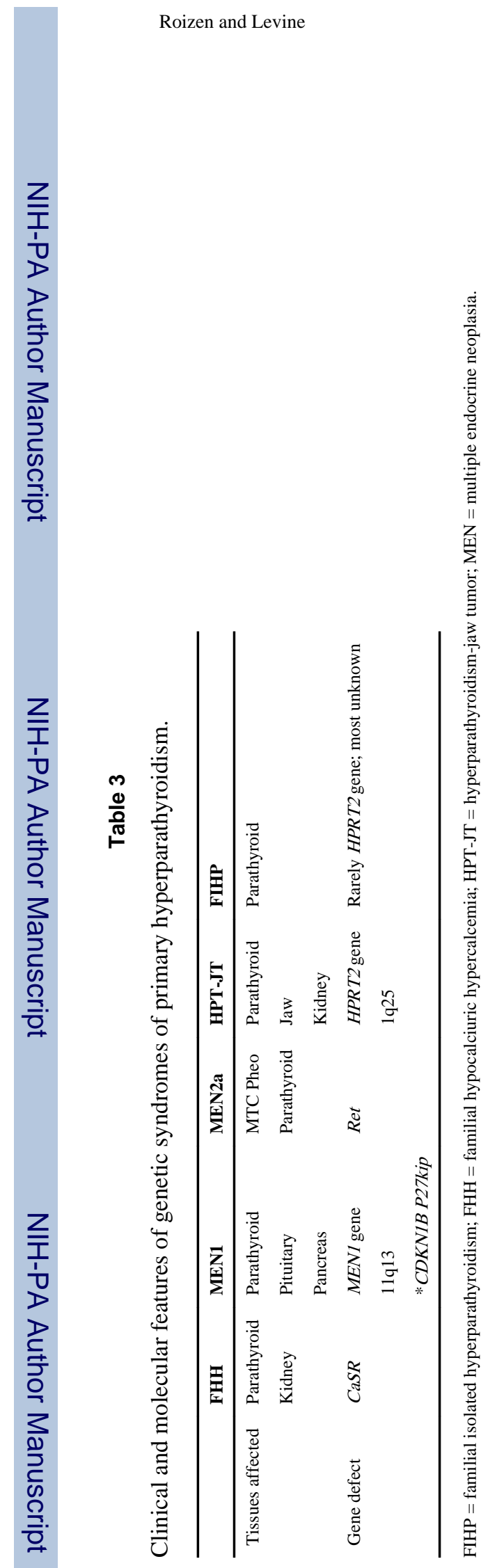

Page 14

J Chin Med Assoc. Author manuscript; available in PMC 2013 July 12. 


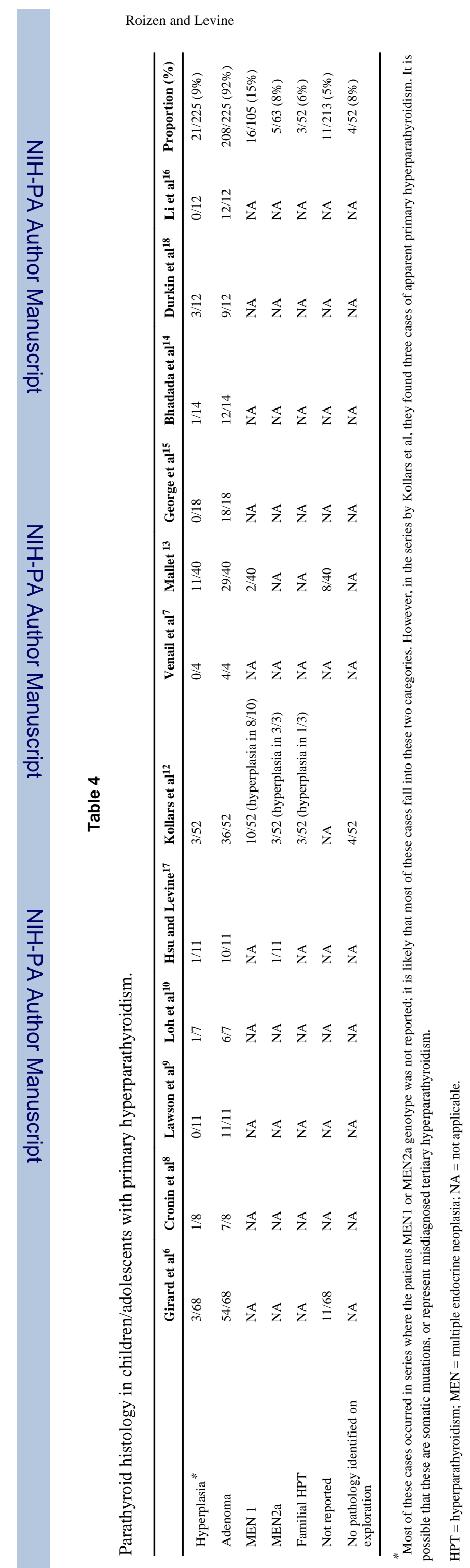

Page 15 
Table 5

Clinical characteristics of infants with neonatal severe hyperparathyroidism (reported in two studies, $n=23$ ).

\begin{tabular}{|c|c|c|c|}
\hline & Norwood et al $^{44}$ & Mallet $^{13}$ & Proportion (percentage) \\
\hline Failure to thrive/feeding difficulties & $8 / 12$ & $2 / 11$ & $10 / 23(43 \%)$ \\
\hline $\begin{array}{l}\text { Skeletal abnormalities (fractures, thoracic deformities, metaphysic irregularities, } \\
\text { cortical dualization, subperiosteal erosion) }\end{array}$ & $9 / 12$ & $10 / 11$ & $19 / 23(83 \%)$ \\
\hline Hyaline membrane disease/respiratory distress & $2 / 12$ & $3 / 11$ & $5 / 23(22 \%)$ \\
\hline Premature birth & $2 / 12$ & NA & $2 / 12(17 \%)$ \\
\hline Hypotonia & NA & $6 / 11$ & $6 / 11(55 \%)$ \\
\hline
\end{tabular}


Roizen and Levine

Page 17

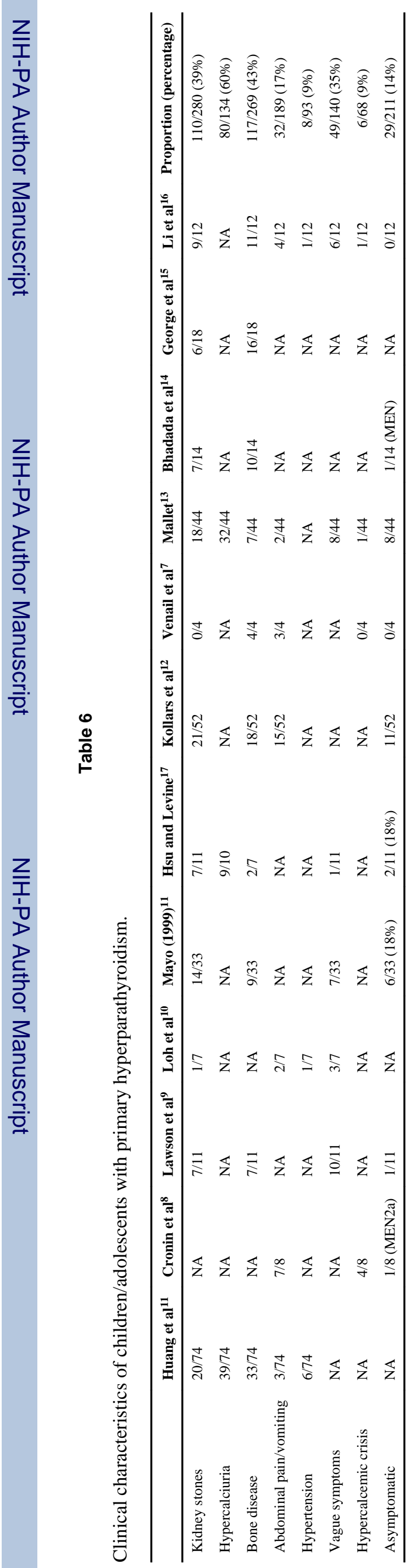

J Chin Med Assoc. Author manuscript; available in PMC 2013 July 12. 


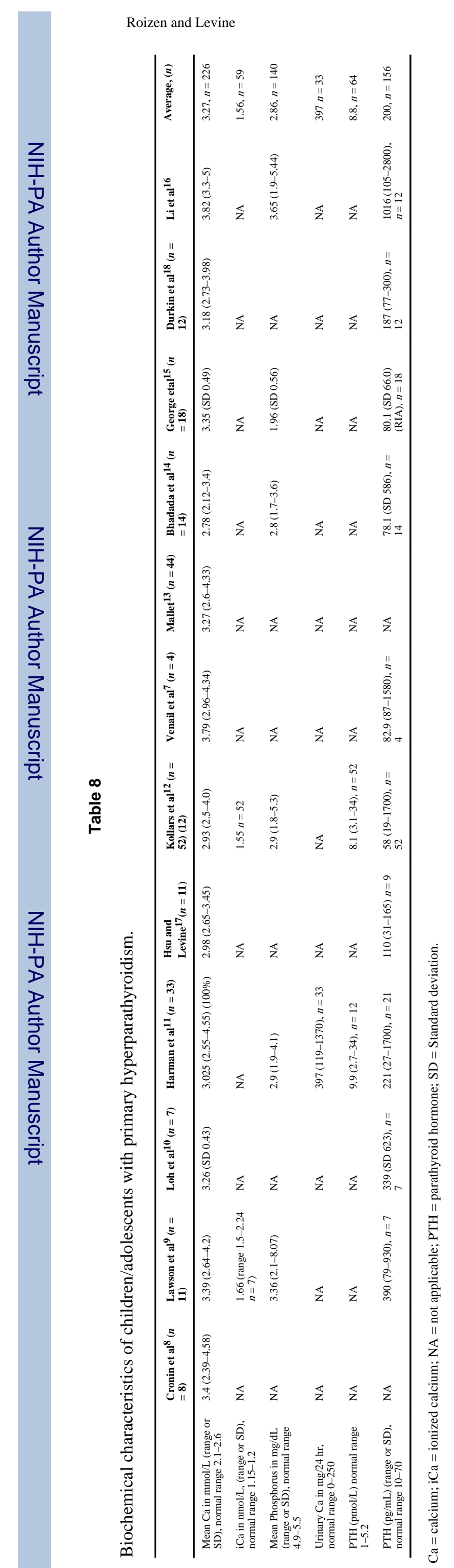

Page 19 


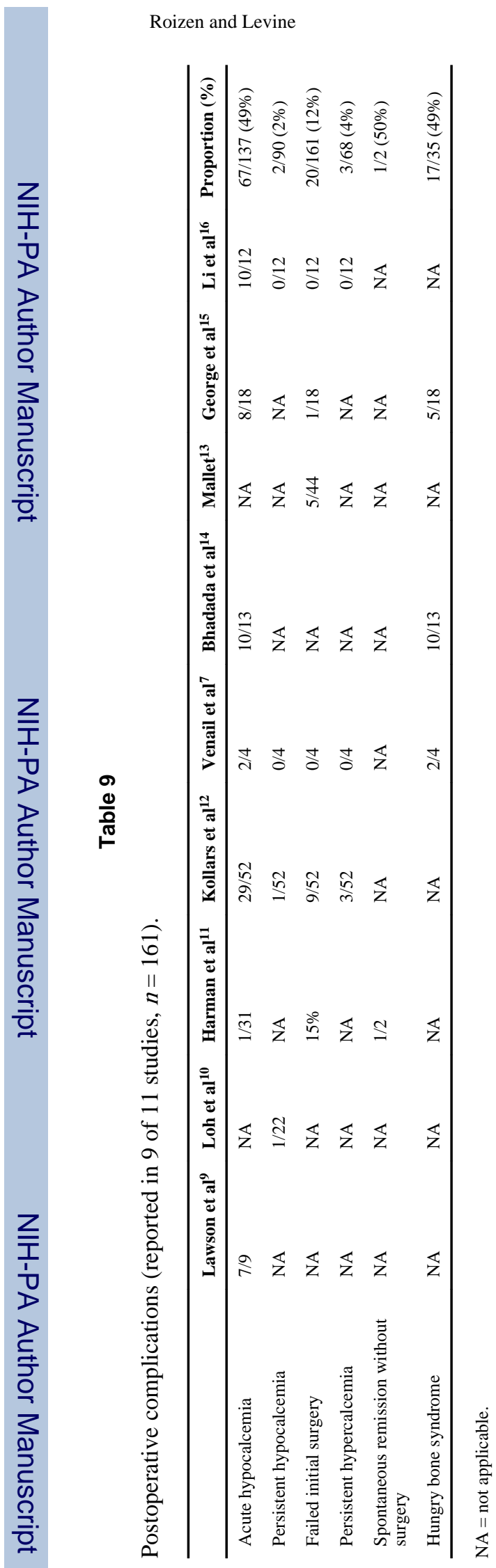

Page 20 
Table 10

Treatment and outcomes in infants with neonatal severe hyperparathyroidism.

\begin{tabular}{lcrr}
\hline & Girard et al $^{6}$ & Mallet $^{13}$ & Total \\
\hline Surgery & $11 / 17$ & $11 / 11$ & $22 / 28(76 \%)$ \\
Fatal (with surgery) & $3 / 9$ & $0 / 11$ & $3 / 20(15 \%)$ \\
Fatal (diagnosis at autopsy) & $8 / 8$ & $0 / 11$ & $8 / 19(42 \%)$ \\
\hline
\end{tabular}

